\title{
Passive characterization and active testing of epoxy bonded regenerators for room temperature magnetic refrigeration
}

Lei, Tian; Navickaité, Kristina; Engelbrecht, Kurt; Barcza, Alexander; Vieyra, Hugo ; Nielsen, Kaspar Kirstein; Bahl, Christian

Published in:

Applied Thermal Engineering

Link to article, DOI:

10.1016/j.applthermaleng.2017.08.152

Publication date:

2017

Document Version

Peer reviewed version

Link back to DTU Orbit

Citation (APA):

Lei, T., Navickaité, K., Engelbrecht, K., Barcza, A., Vieyra, H., Nielsen, K. K., \& Bahl, C. (2017). Passive characterization and active testing of epoxy bonded regenerators for room temperature magnetic refrigeration. Applied Thermal Engineering, 128, 10-19. https://doi.org/10.1016/j.applthermaleng.2017.08.152

\section{General rights}

Copyright and moral rights for the publications made accessible in the public portal are retained by the authors and/or other copyright owners and it is a condition of accessing publications that users recognise and abide by the legal requirements associated with these rights.

- Users may download and print one copy of any publication from the public portal for the purpose of private study or research.

- You may not further distribute the material or use it for any profit-making activity or commercial gain

- You may freely distribute the URL identifying the publication in the public portal 


\title{
1 Passive characterization and active testing of epoxy bonded 2 regenerators for room temperature magnetic refrigeration
}

\author{
Tian Lei ${ }^{1}$, Kristina Navickaitè ${ }^{1}$, Kurt Engelbrecht ${ }^{1}$, Alexander Barcza ${ }^{2}$, Hugo Vieyra ${ }^{2}$, \\ Kaspar K. Nielsen ${ }^{1}$, Christian R. H. Bahl ${ }^{1}$ \\ ${ }^{1}$ Department of Energy Conversion and Storage, Technical University of Denmark, 4000 \\ Roskilde, Denmark \\ ${ }^{2}$ Vacuumschmelze GmbH \& Co. KG, 63450 Hanau, Germany \\ E-mail: tile@dtu.dk

\begin{abstract}
Epoxy bonded regenerators of both spherical and irregular $\mathrm{La}(\mathrm{Fe}, \mathrm{Mn}, \mathrm{Si}){ }_{13} \mathrm{H}_{\mathrm{y}}$ particles have been developed aiming at increasing the mechanical strength of active magnetic regenerators (AMR) loaded with brittle magnetocaloric materials and improving the flexibility of shaping the regenerator geometry. Although the magnetocaloric properties of these materials are well studied, the flow and heat transfer characteristics of the epoxy bonded regenerators have seldom been investigated. This paper presents a test apparatus that passively characterizes regenerators using a liquid heat transfer fluid with an oscillating flow at low Reynolds numbers, simulating the hydraulic working conditions in AMRs. Dimensionless parameters, including friction factor, effectiveness and overall Nusselt number, are presented for the epoxy bonded $\mathrm{La}(\mathrm{Fe}, \mathrm{Mn}, \mathrm{Si})_{13} \mathrm{H}_{\mathrm{y}}$ regenerators and reference packed particle beds. Moreover, a five-layer AMR based on spherical particles is tested actively in a small reciprocating magnetic refrigerator, achieving a no-load temperature span of $16.8{ }^{\circ} \mathrm{C}$ using about $143 \mathrm{~g}$ of epoxy-bonded $\mathrm{La}(\mathrm{Fe}, \mathrm{Mn}, \mathrm{Si}){ }_{13} \mathrm{H}_{\mathrm{y}}$ materials. Simulations based on a one-dimensional (1D) AMR model are also implemented to validate and analyze the results from the active test.
\end{abstract}

Keywords. magnetic refrigeration, active magnetic refrigerator, epoxy bonded regenerator, heat transfer, friction factor

\section{Introduction}

Magnetic refrigeration, which exhibits advantages such as the avoidance of volatile, harmful gases and potentially high efficiency [1], is an alternative to the traditional vapor compression technology. Recently, emerging prototypes that approach the performance of vapor-compression based systems have been reported and they presented high cooling capacity on the order of kilowatts [2, 3] and improved efficiency up to $18 \%$ of the Carnot efficiency [4]. An active magnetic regenerator (AMR) is a porous matrix consisting of magnetocaloric materials (MCMs), in which the fluid exchanges heat with the solid matrix during a periodical reciprocating flow coupled to a varying magnetic field. The refrigeration cycle of an AMR consists of four steps [5, 6]: the magnetization process associated with the temperature increase in the MCM; the cold-to-hot blow that cools the porous matrix by rejecting heat to the ambient; 
the demagnetization process resulting in a further temperature decrease; the hot-to-cold blow where the fluid absorbs a cooling load and the MCM returns to its original temperature. During the two blows, the inlet fluid temperatures at the hot and cold ends are kept constant as $T_{\mathrm{h}}$ and $T_{\mathrm{c}}$, the hot and cold reservoir temperatures, respectively. After several cycles, a temperature span $\Delta T=T_{\mathrm{h}}-T_{\mathrm{c}}$ is built up along the regenerator and the system reaches a periodic steady state. The enthalpy differences at the cold and hot ends are the cooling capacity and the heat dissipation, respectively. The concept of heat regeneration allows materials arranged along the temperature gradient to operate at their own thermodynamic cycles, which realizes a temperature span several times larger than the adiabatic temperature change, $\Delta T_{\mathrm{ad}}$, of the MCMs.

In order to improve the cooling performance, much effort has been devoted to developing magnetocaloric materials and shaping these into regenerators with suitable porous geometries. The derivatives of $\mathrm{La}(\mathrm{Fe}, \mathrm{Si})_{13}$ [7], including $\mathrm{LaFeCoSi}[8]$ and $\mathrm{La}(\mathrm{Fe}, \mathrm{Mn}, \mathrm{Si})_{13} \mathrm{H}_{\mathrm{y}}$ [9, 10], are promising MCMs with a first order phase transition (FOPT), which exhibit a large peak in isothermal entropy change, moderate adiabatic temperature change and tunable Curie temperatures. Both experimental and theoretical studies $[3,11]$ show that proper layering of $\mathrm{La}(\mathrm{Fe}, \mathrm{Si})_{13}$ materials in AMRs could realize an outstanding cooling performance. However, many of these materials are brittle and can break during the cycling of the magnetic field, which may lead to problems such as mechanical instability and possible degradation of the magnetocaloric effect [12]. The possible reason of the cracking lies in the significant volume change up to $1 \%$ associated with the phase transition [13] and the magneto-structural transitions. Therefore, epoxy bonded regenerators have been developed to increase the overall mechanical strength $[3,14,15]$ and to facilitate building a monolithic MCM regenerator [16].

Richard et al. [16] bonded Gd and GdTb flakes with a thin coating of epoxy to form monolithic layers in an AMR, which realized a no-load temperature span near to $20^{\circ} \mathrm{C}$. Jacobs et al. [3] introduced the epoxy-connection process to fabricate six-layer $\mathrm{LaFeSiH}$ regenerators and tested them in a rotary magnetic refrigeration device. This refrigerator realized a cooling power of around $2500 \mathrm{~W}$ over a span of $11{ }^{\circ} \mathrm{C}$ with a coefficient of performance (COP) of approximately 2. Pulko et al. [14] constructed epoxy-bonded LaFeCoSi plates, which maintained the mechanical integrity after 90,000 cycles of applying magnetic field. A no-load temperature span of about $10^{\circ} \mathrm{C}$ was achieved in a magnetic refrigerator using these plates. Neves Bez et al. [15] tested epoxy bonded AMRs using 1 and 2 layers of $\mathrm{La}(\mathrm{Fe}, \mathrm{Mn}, \mathrm{Si})_{13} \mathrm{H}_{\mathrm{y}}$, which achieved a maximum no-load temperature span of $13^{\circ} \mathrm{C}$. Note that a technique of compositing magnetocaloric and metal by hot pressing also has the function of increasing the mechanical stability potentially [17]. However, most of the studies focus on active testing of the epoxy bonded regenerators, and the investigation of the flow and heat transfer characteristics of such regenerators is seldom done. Besides, the particles used in these epoxy bonded regenerators were usually irregular and testing of spherical particles has not yet been reported. Therefore, a passive characterization of the epoxy bonded regenerators is presented in the first part of this article, followed by an active test of a five-layer AMR using spherical particles as the second part. Herein, "passive" means that no magnetic field is applied and in contrast "active" represents testing the cooling performance of AMRs with the magnet assembly.

A quantitative study based on the technique of entropy production minimization [18] has shown that viscous dissipation and imperfect heat transfer are the two mechanisms that present the largest irreversibility inside AMRs. The viscous dissipation is associated with the large pump power and high pressure drop, which reduce efficiency and require thicker housing walls, wasting more magnetized volume. In addition, perfect heat transfer is impossible and there is always a certain temperature difference between the fluid and the solid bed. Enhancing the heat transfer and decreasing the flow 
resistance simultaneously is always challenging. Therefore, the dimensionless parameters such as the friction factor $f_{\mathrm{F}}$ and the Nusselt number $\mathrm{Nu}$ are of essential interest, as they are tightly connected to both irreversible effects. In the passive test, the friction factor could be calculated from the measured pressure drop over the regenerator in either unidirectional or oscillating flow. Moreover, the heat transfer coefficient $h_{\mathrm{f}}$ and $\mathrm{Nu}$ in the convective flow through the porous regenerator could be estimated using different methods, including the unidirectional flow test with constant wall temperature / heat flux, single blow test [19], and the oscillating flow test [20, 21]. In the single blow test, a fluid with constant temperature is blown through the regenerator that starts at a uniform temperature different from the inlet fluid and the response of the outflow temperature is recorded for deducing the heat transfer coefficient. Engelbrecht [22] and Frischmann et al. [23] presented experimental results for packed sphere beds in the single blow test. Under oscillating flow condition, Schopfer [20] studied the thermal-hydraulic properties of the liquid-saturated regenerators. The friction factor and the Nusselt number in the regenerators with microchannels and packed beds were estimated in experiments based on a harmonic approximation technique. Trevizoli et al. [21] constructed a laboratory apparatus and presented the pressure drop, the pumping power and the effectiveness of passive regenerators. The effectiveness is the heat transfer efficiency of a regenerator and is defined as the ratio of the amount of heat that transferred during a blow process to the maximum possible amount of heat transfer.

In this study, two groups of regenerators, including epoxy bonded regenerators using irregular or spherical $\mathrm{La}(\mathrm{Fe}, \mathrm{Mn}, \mathrm{Si})_{13} \mathrm{H}_{\mathrm{y}}$ particles, as well as reference regenerators packed with stainless steel (SS) particles, are characterized in a passive test apparatus. The experiments are run with an oscillating flow in the low Reynolds number region. The dimensionless group consisting of the friction factor $f_{\mathrm{F}}$, the effectiveness $\eta$, and the overall Nusselt number $\mathrm{Nu}_{\mathrm{o}}$ is deduced and presented, based on the measured pressure drop and the temperature profiles. Furthermore, an AMR using five layers of spherical $\mathrm{La}(\mathrm{Fe}, \mathrm{Mn}, \mathrm{Si})_{13} \mathrm{H}_{\mathrm{y}}$ particles is tested actively and the experimental results are validated with the simulations based on an established 1D AMR model.

\section{Passive characterization of epoxy bonded regenerators}

\subsection{Test apparatus and methodology}

The passive regenerator test apparatus is composed of four main sections: the regenerator test section, the oscillating flow generator, the cold heat exchanger with a cold reservoir and the hot heat exchanger with an electric heater. The schematic diagram and a photograph of the test apparatus are shown in Figure 1 (a) and (b), respectively. In detail, the regenerator test section includes a porous regenerator bed (REG), four check valves (CV), thermocouples (T) and two piezoelectric pressure gauges (P). The oscillating flow generator is a motor-crank system (MT) connected to two cylinders (CYL 1 and 2). The displacement of the cylinders is measured by a linear encoder. The cold heat exchanger (CHX) is a double-pipe type. The cold water with a constant temperature is circulating from the cold reservoir to cool down the thermal liquid in the inner tube. The hot heat exchanger (HHX) for heating up the fluid is made by inserting and sealing an electrical cartridge heater in a small insulated chamber.

The reciprocating movement of the two cylinders generates the oscillating flow through the porous regenerator. During the cold-to-hot blow, the fluid is pushed from CYL1, cooled down by CHX, blown through CV1-REG-CV4, and then stored in CYL2. A similar flow pattern is seen in the hot-to-cold blow, and the fluid is heated up by the electric heater in the HHX. On each side of the regenerator, two check valves are set to separate the inflow and outflow, ensuring unidirectional flows in both heat exchangers. By using the check valve system, the dead volume is reduced to $4 \%$ of the regenerator 
volume. The dead volume is an empty space where the fluid mixes freely without the contact with the solid, and it causes the irreversible loss. After several cycles, the oscillating flow system will reach a periodic steady state with a stable temperature span for a certain heating power. For each steady state, the temperature profiles along the regenerator, the heating power and the pressure drop are recorded for further analysis. E-type thermocouples, installed as shown in Figure 1, are calibrated in a water bath before installation. The measurement error is $\pm 0.3{ }^{\circ} \mathrm{C}$ and the response time is estimated to be less than $0.15 \mathrm{~s}$, which is the time required to reach $63 \%$ of an instantaneous temperature change. The temperature data are recorded by a NI (National Instruments) 9213 thermocouple module and a NI cDAQ 9174 acquisition device. The calibrated pressure gauges at both ends have an accuracy of $0.25 \%$ of the full scale and the signal is acquired by a NI 9203 current module. The response time of the pressure gauges is $0.5 \mathrm{~ms}$. The power supply for the heater has meter accuracies of $0.1 \%$ in voltage and $0.3 \%$ in current. To reduce the heat loss to the ambient, all the components are thermally insulated by foam insulation tubes.
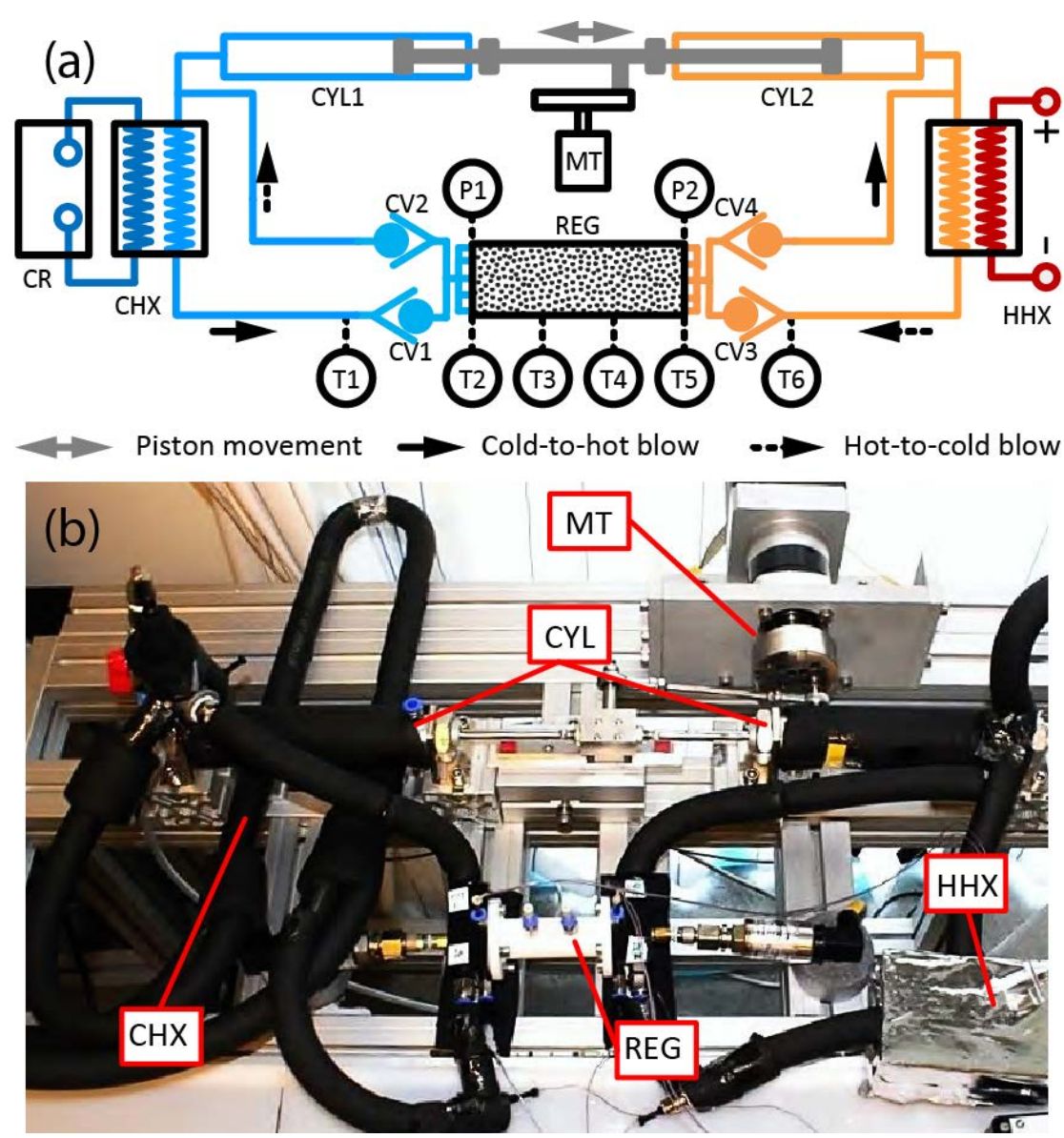

Figure 1. (a) Schematic diagram and (b) photograph of the passive regenerator test apparatus. The labels represent: CHX cold heat exchanger; CR cold reservoir with circulating pump; CV check valve; CYL

cylinder; HHX hot heat exchanger; MT motor and crank; P pressure gauge; REG regenerator; T thermocouple. The solid and dashed arrows show the flow direction during two blows, respectively.

Figure 2 shows an example of the pressure drop data as a function of time, as well as the piston velocity calculated from the measured piston displacement. The fluid and regenerator temperatures are held about $21^{\circ} \mathrm{C}$ during the pressure drop test. Both curves behave similarly to the sinusoidal wave according to the crank design. The piston velocity is approximately $v_{\mathrm{p}}=0.5 S_{\mathrm{p}} \omega \sin \omega t$ and the mass flow rate is $\dot{m}_{\mathrm{f}}=0.5 \rho_{\mathrm{f}} A_{\mathrm{p}} S_{\mathrm{p}} \omega \sin \omega t . A_{\mathrm{p}}$ and $S_{\mathrm{p}}$ are the cross sectional area and the stroke of the piston; $\omega$ is the 
162

163

164

165

166

167

168

169

170

171

172

173

174

175

176

177

178

179

180

181

182

183

184

185

186

187

188

189

angular speed; $\rho_{\mathrm{f}}$ is the fluid density. There is a certain phase difference (about $0.1 \mathrm{~s}$ ) between the piston velocity and the pressure drop over the regenerator. It may be because the measurements with the encoder and pressure gauges are performed with different acquisition components that were not strictly synchronized. Besides, there are some bubbles taking an estimated volume fraction less than $2 \%$ trapped in the system, which can also influence the phase difference. The maximum pressure drop and the maximum superficial velocity $v_{\mathrm{S}}$, are used to calculate the friction factor $f_{\mathrm{F}}$ and the Reynolds number $\mathrm{Re}_{\mathrm{h}}$ by:

$$
\begin{aligned}
& v_{\mathrm{s}}=\frac{\dot{m}_{\mathrm{f}}}{\rho_{\mathrm{f}} A_{\mathrm{c}}} \\
& f_{\mathrm{F}}=\frac{\Delta P}{L} \frac{2 D_{\mathrm{h}}}{\rho_{\mathrm{f}} v_{\mathrm{s}}^{2}} \\
& \operatorname{Re}_{\mathrm{h}}=\frac{\rho_{\mathrm{f}} v_{\mathrm{s}} D_{\mathrm{h}}}{\mu_{\mathrm{f}}}
\end{aligned}
$$

where $A_{\mathrm{c}}, D_{\mathrm{h}}, \mu_{\mathrm{f}}$, and $L$ are the cross sectional area, hydraulic diameter, dynamic viscosity and regenerator length, respectively. Note that $\mathrm{Re}_{\mathrm{h}}$ is based on the hydraulic diameter $D_{\mathrm{h}}$ and the superficial velocity $v_{\mathrm{s}}$. Note that the superficial velocity is based on the cross sectional area, which is different from the real flow velocity in the interval between the particles, so-called interstitial velocity.

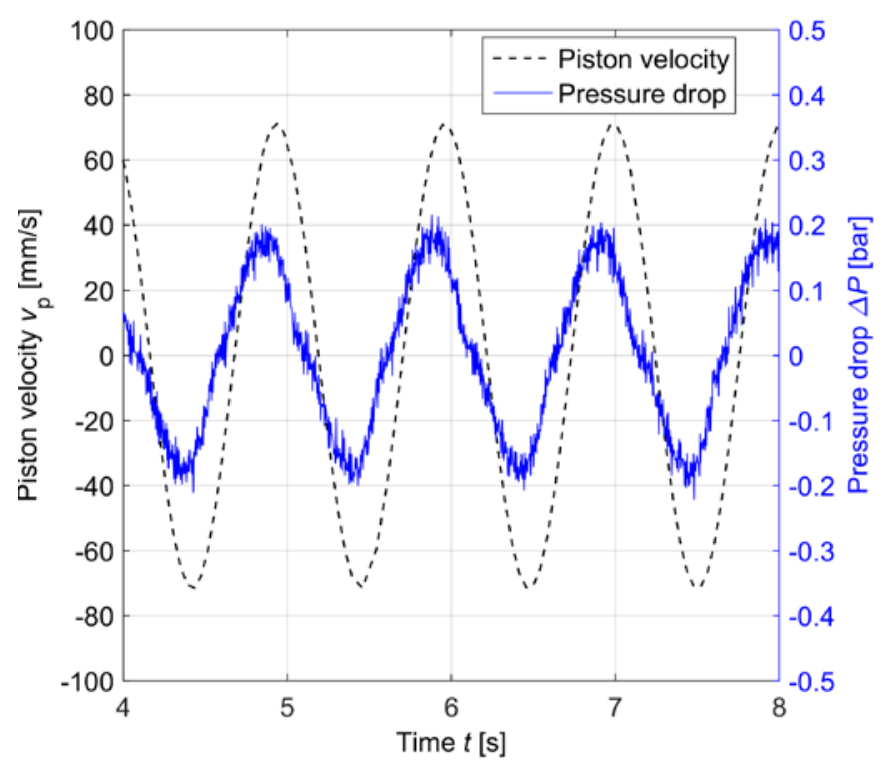

Figure 2. Example of pressure drop and piston velocity during a typical passive experiment.

Dynamic temperature profiles over the regenerator with an oscillating flow are illustrated in Figure 3, where T1 - T6 represent the positions from the cold to hot end as shown in Figure 1 (a). The temperature information is used to estimate the effectiveness, as mentioned above. Assuming that the specific heat capacity of the fluid is temperature independent and the flows are balanced, the effectiveness $\eta$ in each blow period is [21]:

$$
\begin{aligned}
& \eta_{\mathrm{c}}=\frac{2 / \tau \int_{0}^{\tau / 2} T_{\mathrm{f}, \mathrm{h}} d t-T_{\mathrm{c}}}{T_{\mathrm{h}}-T_{\mathrm{c}}} \\
& \eta_{\mathrm{h}}=\frac{T_{\mathrm{h}}-2 / \tau \int_{\tau / 2}^{\tau} T_{\mathrm{f}, \mathrm{c}} d t}{T_{\mathrm{h}}-T_{\mathrm{c}}}
\end{aligned}
$$


where $T_{\mathrm{f}, \mathrm{h}}, T_{\mathrm{f}, \mathrm{c}}, T_{\mathrm{h}}, T_{\mathrm{c}}$, and $\tau$ are the outflow temperatures at hot and cold ends, the inflow temperatures at both ends and the cycle period. It is assumed that the cold-to-hot blows takes place from $t=0$ to $\tau / 2$. In Figure 3, $T_{\mathrm{c}}, T_{\mathrm{f}, \mathrm{c}}, T_{\mathrm{f}, \mathrm{h}}$, and $T_{\mathrm{h}}$ are $\mathrm{T} 1, \mathrm{~T} 2$, T5, and T6, respectively. An ideal regenerator with infinite solid mass gives an effectiveness of 1 , while real regenerators give $\eta$ less than 1 , as the outflow is always lower than the end (reservoir) temperature.

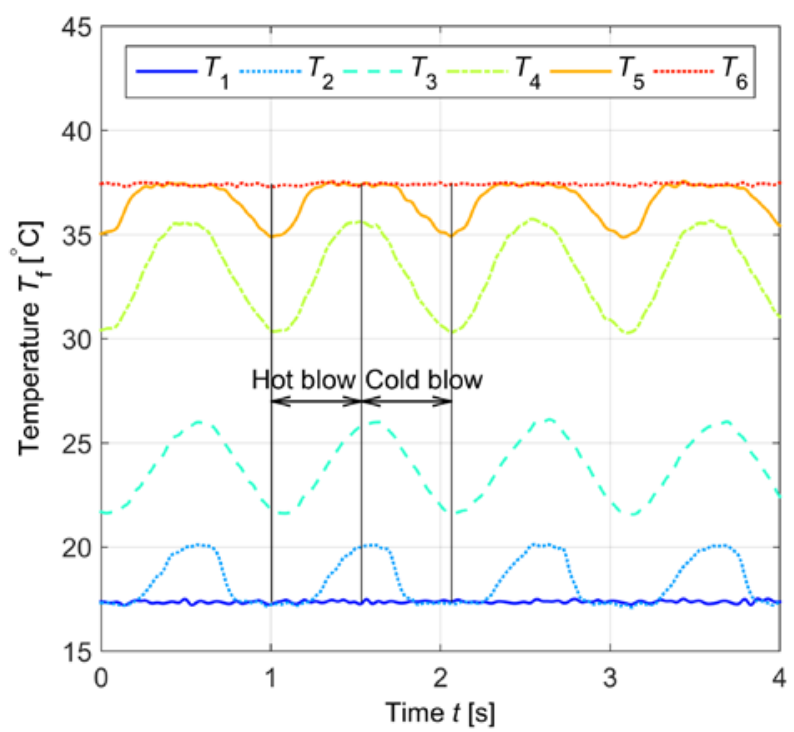

$$
U=\frac{\rho_{\mathrm{f}} c_{\mathrm{f}} A_{\mathrm{p}} S_{\mathrm{p}}}{m_{\mathrm{s}} c_{\mathrm{s}}+\rho_{\mathrm{f}} V_{\mathrm{r}} \varepsilon c_{\mathrm{f}}}
$$

where $c_{\mathrm{f}}, c_{\mathrm{s}}, m_{\mathrm{s}}$ and $V_{\mathrm{r}}$ are the specific heat capacity of the fluid, specific heat capacity of the solid, solid mass and regenerator volume, respectively.

The effectiveness is a function of the utilization ratio and number of transfer units (NTU), that is, $\eta=f(U, \mathrm{NTU})$. NTU describes the ratio of the amount of heat transferred between the solid and the fluid to the thermal mass of the fluid moved:

$$
\mathrm{NTU}=\frac{h_{\mathrm{f}} a_{\mathrm{s}} V_{\mathrm{r}}}{\dot{m}_{\mathrm{f}} c_{\mathrm{f}}}
$$

where $h_{\mathrm{f}}$ and $a_{\mathrm{s}}$ are the convective heat transfer coefficient and the specific surface area, respectively. In general, high effectiveness is obtained with high NTU and low utilization ratio. High NTU means more heat is transferred and low utilization ratio indicates that less fluid is blown through the regenerator bed. Both effects lead to an outflow temperature closer to the reservoir temperature, resulting in an effectiveness closer to 1 . Many studies investigate the effectiveness of a regenerator by either numerical modeling [24] or simplified deduction. In this study, we use a 1D numerical model to obtain the relation 
$\eta=f(U, \mathrm{NTU})$. By turning off the magnetocaloric effect and assuming a constant NTU in a 1D AMR model [22, 25], the two energy equations of the solid and the fluid in the passive regenerator become:

$$
\begin{gathered}
\frac{\partial}{\partial x}\left(k_{\mathrm{stat}} A_{\mathrm{c}} \frac{\partial T_{\mathrm{s}}}{\partial x}\right)+\frac{\mathrm{NTU} \dot{m}_{\mathrm{f}} c_{\mathrm{f}}}{L}\left(T_{\mathrm{f}}-T_{\mathrm{s}}\right)=A_{\mathrm{c}}(1-\varepsilon) \rho_{\mathrm{s}} c_{\mathrm{s}} \frac{\partial T_{\mathrm{s}}}{\partial t} \\
\frac{\partial}{\partial x}\left(k_{\mathrm{disp}} A_{\mathrm{c}} \frac{\partial T_{\mathrm{f}}}{\partial x}\right)-\dot{m}_{\mathrm{f}} C_{\mathrm{f}} \frac{\partial T_{\mathrm{f}}}{\partial x}-\frac{\mathrm{NTU} \dot{m}_{\mathrm{f}} c_{\mathrm{f}}}{L}\left(T_{\mathrm{f}}-T_{\mathrm{s}}\right)+\left|\frac{\partial P}{\partial x} \frac{\dot{m}_{\mathrm{f}}}{\rho_{\mathrm{f}}}\right|=A_{\mathrm{c}} \varepsilon \rho_{\mathrm{f}} C_{\mathrm{f}} \frac{\partial T_{\mathrm{f}}}{\partial t}
\end{gathered}
$$

where $T_{\mathrm{s}}, T_{\mathrm{f}}, x, A_{\mathrm{c}}, L, k_{\mathrm{stat}}, k_{\mathrm{disp}}$ and $\partial P / \partial x$ are the solid temperature, fluid temperature, axial position, cross sectional area, regenerator length, static thermal conductivity, thermal conductivity due to fluid dispersion, and pressure drop per unit length. Solving the two equations numerically gives the dynamic temperature profiles, which can be used to calculate the effectiveness. With this relation, the overall number of transfer units $\mathrm{NTU}_{\mathrm{o}}$ can be back-calculated from the measured effectiveness directly. This index describes the overall heat transfer performance of the regenerator, as the fluid velocity varies in the oscillating flow. Substituting $\mathrm{Nu}=h_{\mathrm{f}} D_{\mathrm{h}} / k_{\mathrm{f}}$ into Eqn. (7) gives the overall Nusselt number $\mathrm{Nu}_{\mathrm{o}}$ :

$$
\mathrm{Nu}_{\mathrm{o}}=\frac{\mathrm{NTU}_{\mathrm{o}}{\overline{\dot{m}_{\mathrm{f}}}}_{\mathrm{f}} D_{\mathrm{h}}}{k_{\mathrm{f}} a_{\mathrm{s}} V_{\mathrm{r}}}
$$

where $k_{\mathrm{f}}$ is the hydraulic diameter and $\overline{\dot{m}_{\mathrm{f}}}$ is the average mass flow rate.

\subsection{Particle characterization and epoxy bonded regenerators}

As revealed in the literature, the cooling performance of the bonded AMRs degraded with an increasing amount of epoxy [15], which is due to the decreasing MCM volume and the possible reduction in the overall heat transfer performance. By improving the formulation of the Amerlock epoxy, the mass can be reduced to as little as $1 \mathrm{wt}$. \%, while maintaining the required mechanical strength. Therefore, $1 \mathrm{wt}$. $\%$ epoxy is applied in the regenerators for the passive test. For future applications, 1-2 wt. \% could be the optimal mass fraction considering the trade-off between the mechanical stability and the cooling performance, as the magnetic field in a real "active" device will challenge the mechanical strength more.

Two groups of $\mathrm{La}(\mathrm{Fe}, \mathrm{Mn}, \mathrm{Si})_{13} \mathrm{H}_{\mathrm{y}}$ particles, irregular and spherical, as shown in Figure 4(a) and (b), were bonded with $1 \mathrm{wt}$. \% epoxy in regenerator housings for the passive test. The micrographs of the particles are taken by a Hitachi TM3000 Scanning Electron Microscope (SEM) and the insets show photographs of the regenerators. The two epoxy bonded regenerators were provided by Vacuumschmelze GmbH \& Co. KG. Most particles in Figure 4(a) have a high degree of irregularity. A particle distribution analysis was done using the image analysis software ImageJ and the equivalent diameter was found from the measured area of about 470 and 530 particles, respectively. The size of irregular particles ranges from 0.2 to $1.0 \mathrm{~mm}$. For $\mathrm{La}(\mathrm{Fe}, \mathrm{Mn}, \mathrm{Si})_{13} \mathrm{H}_{\mathrm{y}}$, only irregular particles have been tested before and there is a lack of investigation on the spherical particles. For the spherical particles in Figure 4(b), the particle size is about $0.3-0.9 \mathrm{~mm}$ and most of the particles are in the diameter range around 0.5-0.8 $\mathrm{mm}$. By fitting the Gaussian distribution, the average particle sizes for both groups are estimated as $0.56 \mathrm{~mm}$ with a standard deviation of $0.21 \mathrm{~mm}$ and $0.58 \mathrm{~mm}$ with a standard deviation of $0.14 \mathrm{~mm}$, respectively. Both materials have Curie temperatures around $20{ }^{\circ} \mathrm{C}$ and densities of about $6900 \mathrm{~kg} / \mathrm{m}^{3}$. In the first regenerator VAC-A, about $79 \mathrm{~g}$ of $\mathrm{La}\left(\mathrm{Fe}, \mathrm{Mn}, \mathrm{Si}_{13} \mathrm{H}_{\mathrm{y}}\right.$ irregular particles with $1 \mathrm{wt}$. \% epoxy is loaded into the 3D-printed nylon housing, while about $73 \mathrm{~g}$ of spherical particles are packed in the second regenerator VAC-B. The housings have a length of $72 \mathrm{~mm}$, an inner diameter of $20 \mathrm{~mm}$, and are printed by the Sinterstation 2500 Plus Selective Laser Sintering (SLS) printer. The housings are further treated with epoxy to be watertight. Due to a low packing density, the regenerators VAC-A and VAC-B have porosities $\varepsilon=1-V_{s} / V_{r}$ around 0.46 and 0.48 , respectively, where $V_{s}$ is the total solid volume including 
the MCM and the epoxy. Furthermore, the specific surface area for each group is estimated by $\mathrm{a}_{\mathrm{s}}=$ $\sum A_{s} / V_{r}{ }^{\prime}$, where $\sum A_{s}$ is the total surface area of about 500 particles and $V_{r}{ }^{\prime}$ is the corresponding regenerator volume. Since most of the groups are spherical particles, $\sum A_{\mathrm{s}}$ can be calculated from the profiles and the equivalent diameters mentioned above. Here the specific surface areas are estimated as 4,640 and 5,030 $\mathrm{m}^{-1}$ for the two regenerators respectively, assuming the contacted points between the particles are very small and the epoxy are coated thinly end evenly.

As the baseline experiments, four different SS particles are also tested, which are 0.4-0.5, 0.5-0.7 mm and 0.8-1.0 mm spherical particles, as well as $1.0 \mathrm{~mm}$ precise balls. The average particles sizes are about 0.45, 0.6, 0.9 and $1.0 \mathrm{~mm}$, and the standard deviations are estimated to be $0.05,0.06,0.05$, and $<0.01$ $\mathrm{mm}$ for each group respectively, using probability distribution fitting. The particle sizes of the first three groups are controlled by sieving. In general, the size deviation is much smaller compared to the $\mathrm{La}(\mathrm{Fe}, \mathrm{Mn}, \mathrm{Si})_{13} \mathrm{H}_{\mathrm{y}}$ particles according to the particle analysis. For these four regenerators, SS particles are loaded randomly into the same housing and stopped by one piece of thin mesh at each end. About 113 - 116 g SS particles are packed into the regenerators, giving porosities around 0.35 - 0.37 although the particle size varies. For the packed particle bed, the hydraulic diameter is calculated by:

$$
D_{\mathrm{h}}=\frac{2 \varepsilon}{3(1-\varepsilon)} D_{\mathrm{p}}
$$

where $D_{\mathrm{p}}$ is the average particle diameter.

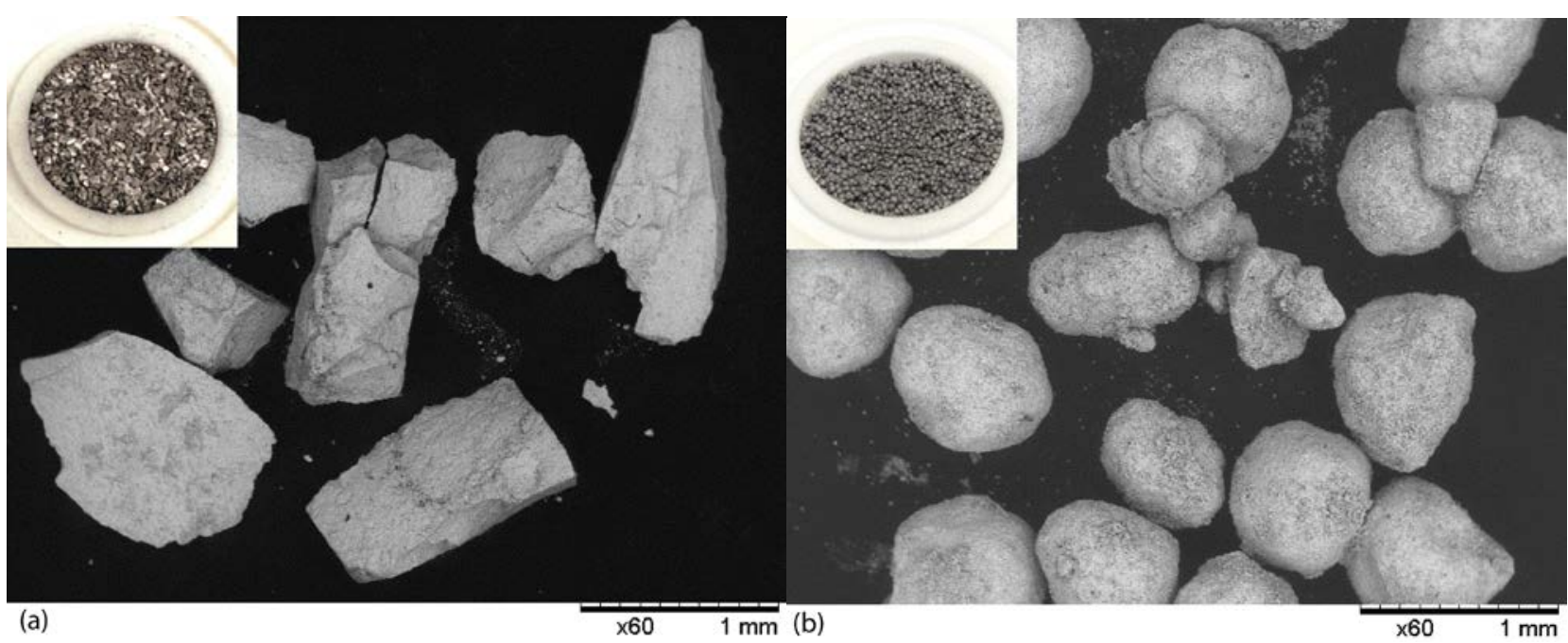

(a) $\mathrm{La}(\mathrm{Fe}, \mathrm{Mn}, \mathrm{Si})_{13} \mathrm{H}_{\mathrm{y}}$ irregular particles in VAC-A

(b) $\mathrm{La}(\mathrm{Fe}, \mathrm{Mn}, \mathrm{Si})_{13} \mathrm{H}_{\mathrm{y}}$ spherical particles in VAC-B

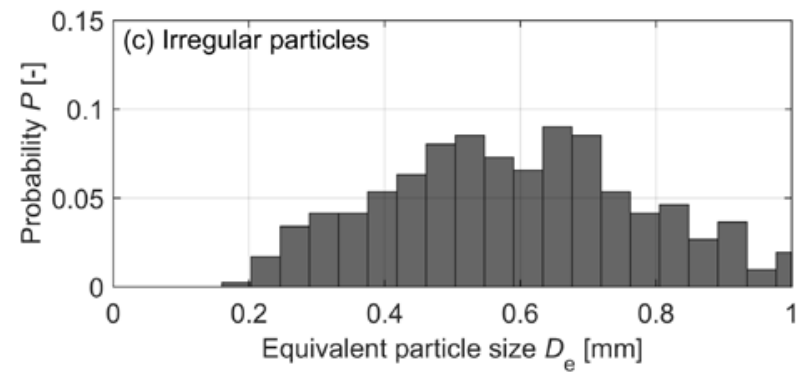

(c) Size distribution of $\mathrm{La}(\mathrm{Fe}, \mathrm{Mn}, \mathrm{Si})_{13} \mathrm{H}_{\mathrm{y}}$ irregular particles

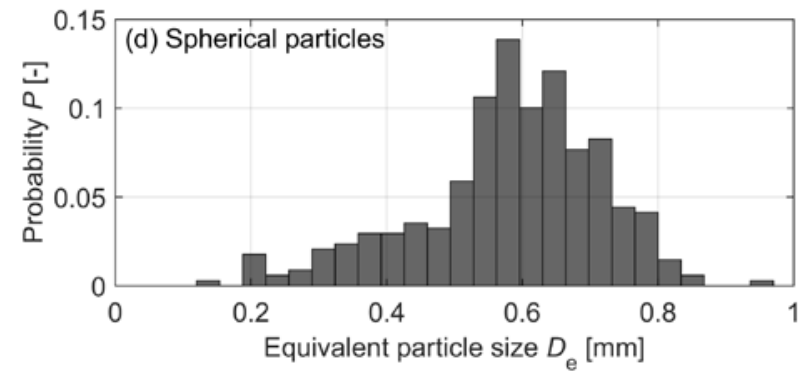

(d) Size distribution of $\mathrm{La}(\mathrm{Fe}, \mathrm{Mn}, \mathrm{Si})_{13} \mathrm{H}_{\mathrm{y}}$ spherical particles 
The specific surface area $a_{\mathrm{s}}$ of a porous media can be expressed as [26]:

$$
a_{\mathrm{s}}=\frac{4 \varepsilon}{D_{\mathrm{h}}}
$$

Eqn. (12) in return can be used to calculate the hydraulic diameter of a porous medium from the porosity and the specific surface area, which are $0.41 \mathrm{~mm}$ and $0.38 \mathrm{~mm}$ for VAC-A and VAC-B, respectively.

\subsection{Experimental results}

In the test, the heat transfer fluid is an aqueous solution with $20 \mathrm{v} / \mathrm{v} \%$ ethylene glycol (EG). Measured on a viscometer (Anton Paar Lovis $2000 \mathrm{M} / \mathrm{ME}$ ), the heat transfer fluid has a density of $1031 \mathrm{~kg} / \mathrm{m} 3$ and a dynamic viscosity of $1.77 \mathrm{mPa} \cdot \mathrm{s}$. The piston stroke $S_{\mathrm{p}}$ is changed from 10 to $45 \mathrm{~mm}$ by adjusting the crank distance and the operating frequency is controlled from 0.5 to $1.25 \mathrm{~Hz}$ by increasing the motor rotation speed. The superficial velocity in the regenerator is strongly related to both the stroke and the frequency, while the utilization ratio mainly depends on the stroke according to the definition in Eqn. (6). In addition, the temperature span is controlled by applying power to the heater.

\subsubsection{Friction factor}

Figure 5 gives the friction factor calculated from the maximum pressure drop data for different regenerators based on Eqns. (2)-(3). During the measurements, the stroke is adjusted from 15 to $40 \mathrm{~mm}$ and the frequencies vary from 0.50 to $1.25 \mathrm{~Hz}$ with a step of $0.25 \mathrm{~Hz}$. The pressure drop $\Delta P$ is velocity dependent, so the measured $\Delta P$ increases with both the stroke and the frequency. The results of the friction factors are compared with the Ergun equation [27] for spherical particles and the modified Ergun equation [28] for irregular particles, which are widely used correlations for calculating the pressure drop over packed beds. Figure 5 shows that the friction factor of the regenerators packed with SS particles fits the Ergun equation quite well, and the average deviation is less than $12 \%$. The friction factor of the epoxy bonded regenerators are also presented and compared with the Ergun equation, which could be extended to the porosity up to 0.46 . The comparison shows that the friction factors of the epoxy bonded regenerators are much higher than those predicted by the Ergun equation. Compared to irregular particles, the spherical ones have relatively lower friction factors, which is preferable for reducing the pump loss and the pressure drop. The $\mathrm{La}\left(\mathrm{Fe}, \mathrm{Mn}, \mathrm{Si}_{13} \mathrm{H}_{\mathrm{y}}\right.$ particles in VAC-A are highly irregular and the particle size is distributed widely for both epoxy bonded regenerators. Furthermore, the epoxy occupies about $4 \%$ of the regenerator volume and it may also block the channels and decrease the overall channel sizes. These effects may introduce a considerable increase in the friction factors of the two epoxy bonded regenerators.

\subsubsection{Heat transfer performance}

Based on Eqns. (4)-(6), the effectiveness and utilization ratio for different regenerators are calculated and presented in Figure 6. The temperature span ranges from 22 to $42^{\circ} \mathrm{C}$ and the operating frequency is about $1 \mathrm{~Hz}$. In order to estimate the utilization ratio, the specific heat capacity of the fluid from the commercial software EES (Engineering Equation Solver) [29] is used. For $\mathrm{La}(\mathrm{Fe}, \mathrm{Mn}, \mathrm{Si})_{13} \mathrm{H}_{\mathrm{y}}$, the temperature dependence of the specific heat capacity $c_{S}$ (as seen in Ref. [25]) is also considered and the average $c_{\mathrm{s}}$ is about $540 \mathrm{~J} /\left(\mathrm{kg} \cdot \mathrm{K}\right.$ ) for a temperature span of $20^{\circ} \mathrm{C}$. In Figure 6 , smaller particles always exhibit higher effectiveness with the same utilization ratio for the packed SS particle beds. This is attributed to the larger specific surface area and the higher overall heat transfer coefficient, and then the higher NTU. A high NTU regenerator is always preferable for the AMR design. However, it requires smaller channel sizes in return, which raises the pressure drop. Thus the trade-off between the flow and heat transfer performance becomes important to the system design. For the two epoxy bonded 
regenerators, although the regenerator mass is lower, the utilization ratios, $U$, are still similar to those for the packed SS particle beds. This is because both solid and fluid thermal masses are included in the calculation of $U$ based on Eqn. (6). VAC-A packed with irregular particles exhibits slightly higher effectiveness than VAC-B with spherical particles, while presenting significantly higher pressure drop during the test. For the spherical particles, the effectiveness can potentially be improved without increasing the pressure drop much by decreasing the particle size and adjusting the size distribution. Therefore, we present the active test of an AMR using the spherical $\mathrm{La}(\mathrm{Fe}, \mathrm{Mn}, \mathrm{Si})_{13} \mathrm{H}_{\mathrm{y}}$ particles to demonstrate the material's active performance. In the experiments, the heating power applied on the hot side of the regenerators is inversely proportional to the effectiveness, as it in fact represents the total enthalpy difference at the hot end and the degree to which the outflow temperature is close to $T_{\mathrm{h}}$.

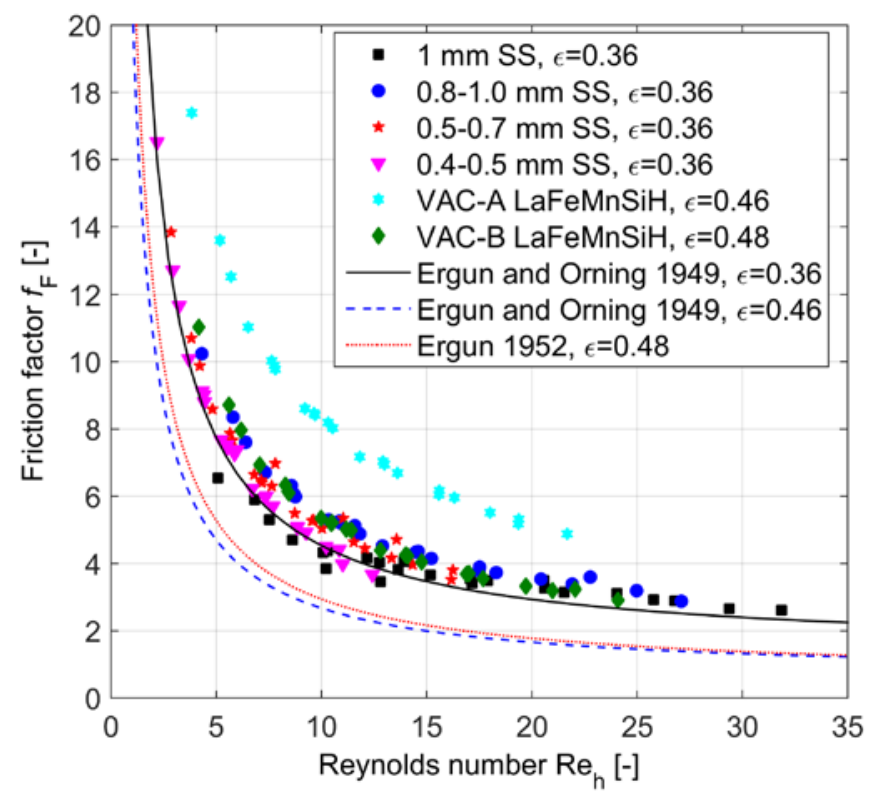

Figure 5. Friction factor as a function of the Reynolds number for different regenerators compared with the Ergun equation.

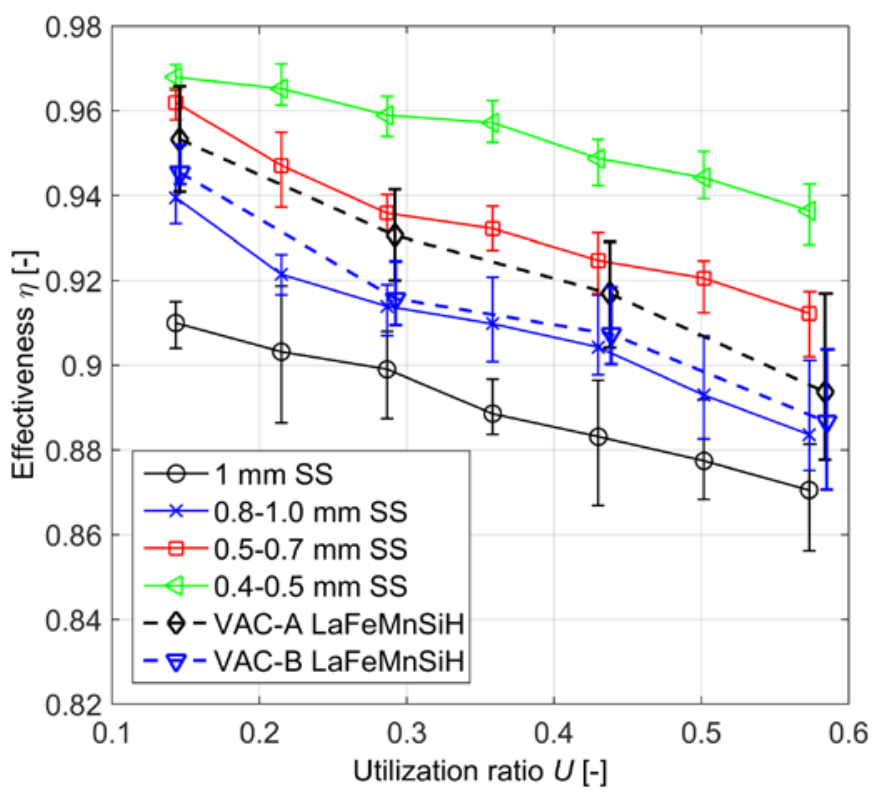

Figure 6. Effectiveness as a function of the utilization ratio for different regenerators. 
356

357

358

359

360

361

362

363

364

365

366

367

368

369

370

371

372

373

374

375

376

Figure 7 gives the relation $\eta=f(U, \mathrm{NTU})$ theoretically based on the $1 \mathrm{D}$ numerical model introduced in Section 2.1. Here the packed SS particle beds are simulated. With smaller utilization ratio and higher NTU, the effectiveness increases. By interpolating the measured effectiveness in Figure 6, the intermediate index $\mathrm{NTU}_{\mathrm{o}}$ can be calculated. For the four regenerators packed with SS particles, average $\mathrm{NTU}_{\mathrm{o}}$ are 8.5, 11.5, 21.3 and 41.4 respectively, increasing with smaller particles. Then VAC-A and VAC-B hold average $\mathrm{NTU}_{\mathrm{o}}$ of 17.8 and 13.0, within the range for SS particles. Furthermore, the overall Nusselt number $\mathrm{Nu}_{\mathrm{o}}$ found from Eqn. (10) is calculated and presented in Figure 8. The same procedure is done in order to obtain $\mathrm{Nu}_{\mathrm{o}}$ for the epoxy bonded regenerators. Herein, the average superficial velocity $\overline{v_{\mathrm{s}}}$ is used to calculate the mean Reynolds number $\mathrm{Re}_{\mathrm{h}, \mathrm{m}}=\rho_{\mathrm{f}} \overline{\mathrm{v}_{\mathrm{s}}} D_{\mathrm{h}} / \mu_{\mathrm{f}}$. As seen in Figure $8, \mathrm{Nu}_{\mathrm{o}}$ increases with higher mean Reynolds number for all the regenerators. Higher $\mathrm{Nu}_{\mathrm{o}}$ is observed with smaller particles and VAC-A in the two groups of regenerators. The data of $\mathrm{Nu}_{\mathrm{o}}$ are also compared to Wakao et al.'s [30] and Engelbrecht's [22] correlations in Figure 8. Wakao et al. [30] did a comprehensive review and proposed a general correlation extending to the low Reynolds number region. For comparison, the Reynolds number based on the particle dimension is modified to that based on the hydraulic diameter here. Engelbrecht [22] presented the heat transfer correlation for a packed bed by the single blow test, which is $\mathrm{Nu}=0.7 \mathrm{Pr}^{0.23} \mathrm{Re}_{\mathrm{h}}{ }^{0.6}$. The plots in Figure 8 show that the experimental curves in this study follow the trend of both correlations from literature, and the data are closer to the latter. Note that Wakao et al. proposed the correlation based on literature data with $\operatorname{Re}_{\mathrm{p}}>100$, equivalent to $\mathrm{Re}_{\mathrm{h}}>38$, and the correlation was extended to the region with $\mathrm{Re}_{\mathrm{h}}<38$ for comparison here.

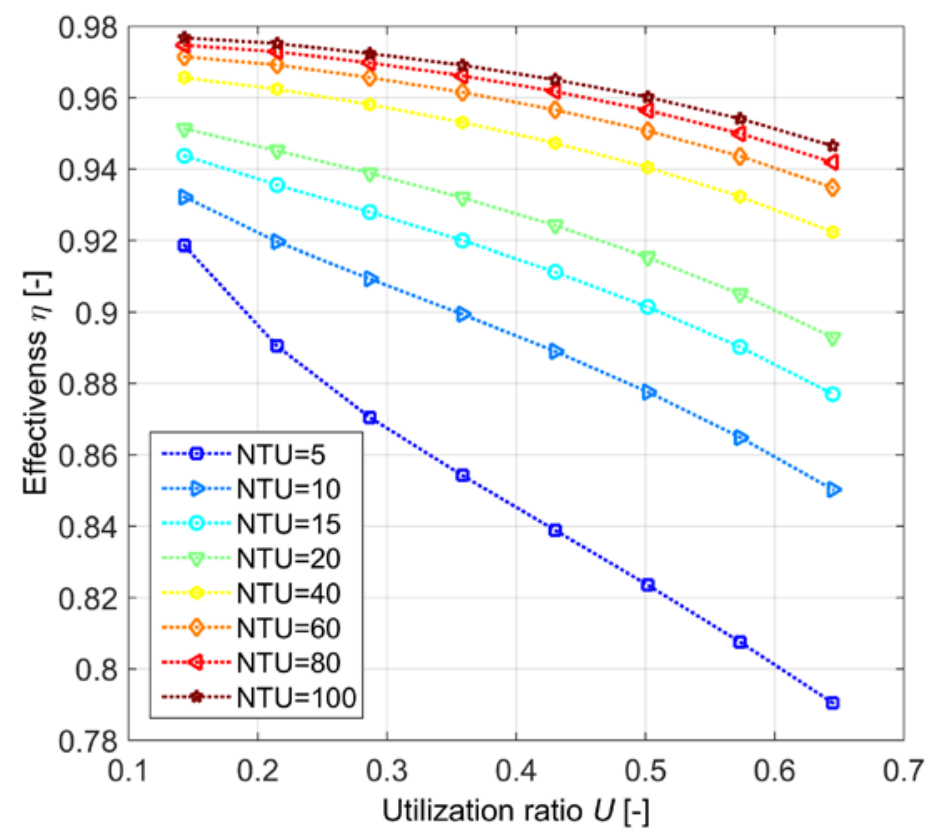

Figure 7. Simulated effectiveness as a function of NTU and the utilization ratio for regenerators using packed SS particles. 


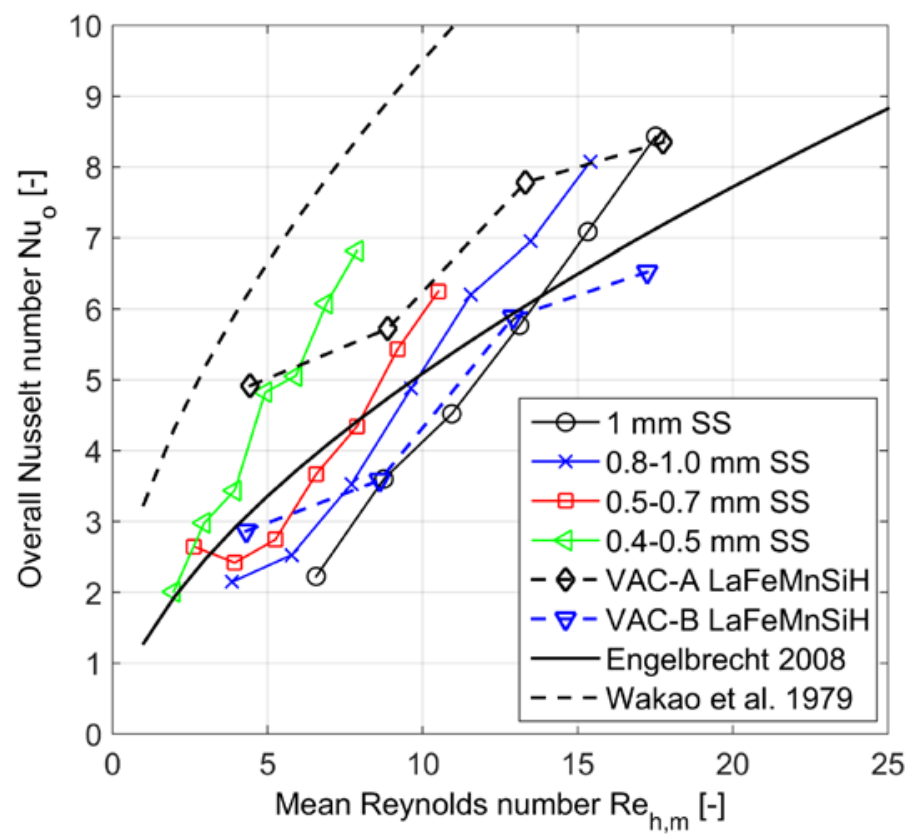

Figure 8. Overall Nusselt number as a function of the mean Reynolds number for different regenerators.

\section{Active test of epoxy bonded regenerators}

\subsection{Test apparatus and $1 D$ numerical AMR model}

An epoxy bonded regenerator using five layers of $\mathrm{La}(\mathrm{Fe}, \mathrm{Mn}, \mathrm{Si})_{13} \mathrm{H}_{\mathrm{y}}$ spherical particles was tested actively in a small-scale reciprocating magnetic refrigerator. This test apparatus was developed at the Technical University of Denmark (DTU) for verifying different AMR concepts [31]. As seen in Figure 9, the whole setup consists of six main components. A Halbach cylinder permanent magnet, which generates an average magnetic flux density around $1.0 \mathrm{~T}$ in the magnetized area, is fixed. A heater at the cold end simulates the cooling load and a hot heat exchanger serves to maintain the hot end temperature. To generate a periodically changing applied magnetic field, the whole regenerator is moved reciprocally into and out of the magnetized area of the magnet by the motor with a linear guide. Synchronized with the applied magnetic field, the moving piston generates an oscillating flow through the regenerator with a certain phase difference, which forms a four-step refrigeration cycle as seen in Figure 10. The cycle period is about 6-8 s, depending on the timing of the different parts of the cycle. Note that it is the magnetic field applied in the middle of the regenerator which is shown in Figure 10. In fact, the applied magnetic field varies in the perpendicular direction, as the field strength is lower at the edge of the magnetized area than that in the centre. The whole apparatus is installed in a temperature controlled cabinet and the hot heat exchanger is in thermal contact with the air inside. Thus the hot end temperature is controlled by adjusting the cabinet temperature. The temperature span is recorded by E-type thermocouples with a measurement error of $\pm 0.3^{\circ} \mathrm{C}$. The current and the voltage applied to the resistance heater are also measured to calculate the cooling load. 


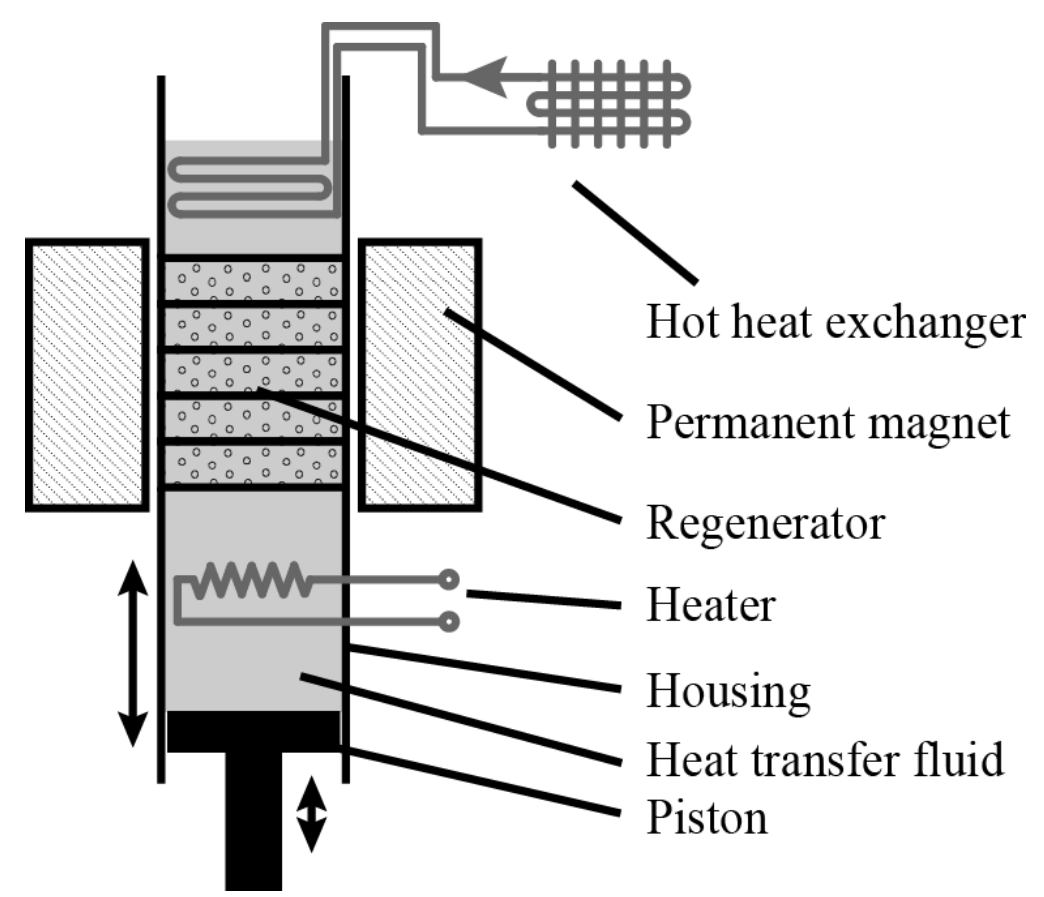

Figure 9. Schematic diagram of the small-scale reciprocating magnetic refrigerator.

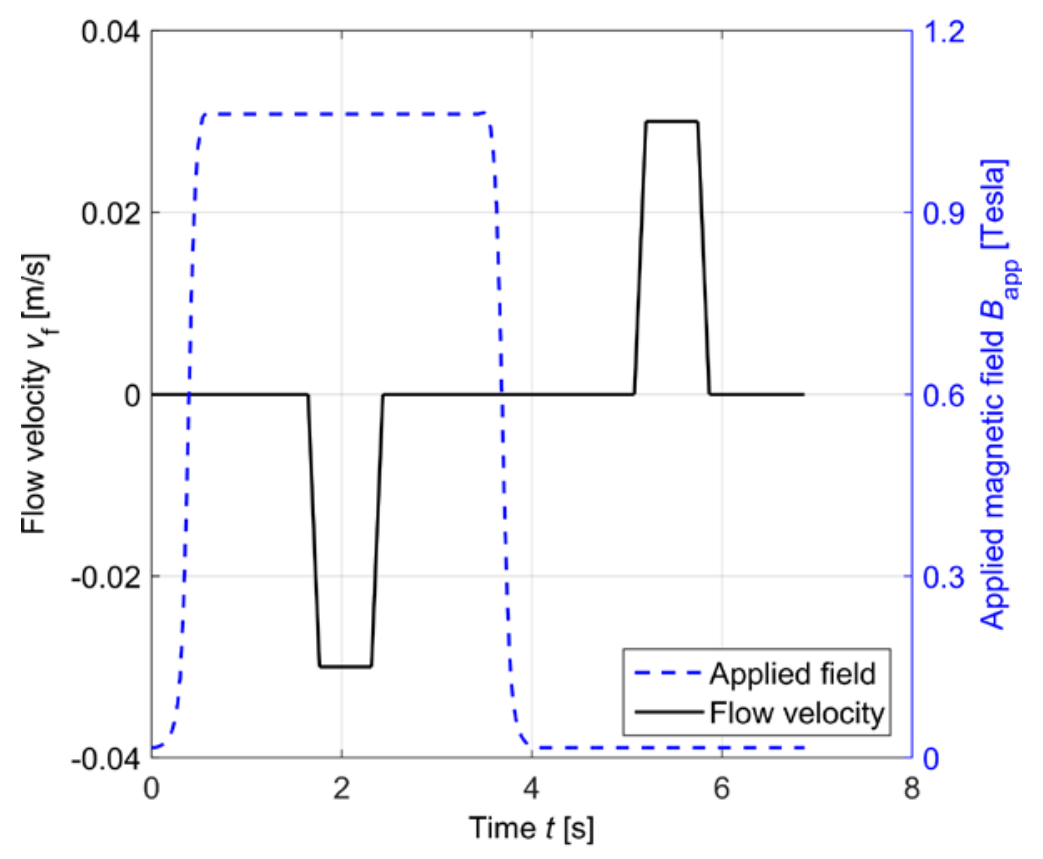

Figure 10. Flow and magnetic field profiles of the small-scale reciprocating magnetic refrigerator.

Simulations of this AMR are implemented based on a 1D numerical model developed at DTU [11, 25]. The AMR model $[22,25]$ is built up based on Eqns. (8) and (9) by using the empirical correlation of the heat transfer coefficient instead of constant NTU and adding a term representing the magnetocaloric transition. This transient model discretizes and solves these two modified energy equations in order to predict the dynamic temperature profiles along the AMR. After reaching steady state within a numerical tolerance, the performance indices, such as the cooling power and COP, can be calculated from the temperature information in the last cycle. The properties of materials and the operating parameters could 
418

be modified according to the active test, making this model flexible to study the AMR performance. Based on an observation that $\Delta S_{\text {iso }}$ of $\mathrm{La}(\mathrm{Fe}, \mathrm{Mn}, \mathrm{Si})_{13} \mathrm{H}_{\mathrm{y}}$ with different $T_{\text {Curie }}$ are similar for the temperature range studied here, an approach of shifting one group of experimental data according to designed $T_{\text {Curie }}$ [25] is used in simulation to determine the magnetocaloric properties of each material. More details of this 1D AMR model are given in Ref. [22, 25]. In the simulation, the demagnetization factor is estimated to be about 0.36 according to the method presented in Ref. [32].

\subsection{Experimental results and validation using $1 D$ AMR model}

In total, about $143 \mathrm{~g}$ of material was loaded into the regenerator housing made of a Perspex tube, which has an inner diameter of $32 \mathrm{~mm}$ and a length of $40 \mathrm{~cm}$. The dimensions of this 5-layer AMR are not the same as VAC-B due to different connection interfaces in two apparatuses and test purposes. About $2 \mathrm{wt}$. $\%$ epoxy is used inside the AMR, corresponding to an estimated volume fraction of about $8 \%$. The Curie temperature of the materials and their volume fractions are summarized in Table 1. A sample of each material (approximately $10 \mathrm{mg}$ ) was characterized on a Lake Shore 7407 Vibrating Sample Magnetometer (VSM). The Curie temperature was defined as the inflection point of the magnetisation, measured in a $10 \mathrm{mT}$ applied field. Note that for first order phase transition materials, the Curie temperatures determined in this way will be lower than those where the peaks of $\Delta S_{\text {iso }}$ or $\Delta T_{\text {ad }}$ appear. The average spacing of the Curie temperature is about $2.0^{\circ} \mathrm{C}$. The heat transfer fluid is $2 \mathrm{v} / \mathrm{v} \%$ of the commercial anti-corrosion additive ENTEK FNE in an aqueous solution [33]. A low concentration such as $1-2 \mathrm{v} / \mathrm{v} \%$ has proven sufficient to protect the magnetocaloric materials well in a four-month static corrosion test at DTU. The stroke $S_{\mathrm{p}}$, the hot end temperature $T_{\mathrm{h}}$ and the cooling load $\dot{Q}_{\mathrm{c}}$ are adjusted to investigate the cooling performance of this five-layer AMR. In both passive and active tests, the epoxy bonded regenerators are quite stable and maintain mechanical integrity well after testing for two months. Due to the first order characteristics of the materials, the specific heat is strongly dependent on the temperature. This makes the utilization always change for different temperature spans. Therefore the piston stroke is presented mainly instead of the utilization. The roughly estimated utilization varies from 0.4 to 0.8 with the piston stroke from 7 to $15 \mathrm{~mm}$.

Table 1. Curie temperatures of the materials and volume fraction in each layer.

\begin{tabular}{cccccc}
\hline Layer sequence & 1 & 2 & 3 & 4 & 5 \\
\hline Curie temperature $\left[{ }^{\circ} \mathrm{C}\right]$ & 11.4 & 14.5 & 16.2 & 17.5 & 19.9 \\
Volume fraction $[\%]$ & 12.6 & 22.4 & 21.3 & 22.2 & 21.5 \\
\hline
\end{tabular}

Figure 11 presents the no-load temperature span $\Delta T$ over the epoxy bonded regenerator as a function of the hot end temperature as well as the simulation results. This 5-layer regenerator achieves a maximum no-load temperature span of $16.8^{\circ} \mathrm{C}$ when the hot end temperature is about $25^{\circ} \mathrm{C}$, which is larger than that of $13.5^{\circ} \mathrm{C}$ for a two-layer regenerator using similar materials [15]. The span obtained here is also larger than $8.9{ }^{\circ} \mathrm{C}$ for $\mathrm{Gd}$ and $8.5^{\circ} \mathrm{C}$ for 2-layer $\mathrm{La}(\mathrm{Fe}, \mathrm{Co}, \mathrm{Si})_{13}$ tested in the same apparatus [31]. Note there are no check valves to separate the flows in both ends, and the dead volume is larger than that in the passive test setup. The simulation results are slightly higher than the experimental data and fit the trends quite well. Both experiments and simulations show that the no-load temperature span is quite sensitive to the hot end temperature as discussed and analyzed in Ref. [25]. This is attributed to the strong temperature dependence of the magnetocaloric effect and the narrow working temperature region for the FOPT MCMs. The materials in some layers may not be fully "activated" when the working temperature deviates from the best region. 
462 463 464 465 466

Figure 12 shows that the impact of the piston stroke $S_{\mathrm{p}}$ on the no-load temperature span $\Delta T$ is quite small in this case. $\Delta T$ only slightly increases when $S_{\mathrm{p}}<10 \mathrm{~mm}$ and reaches the maximum at a stroke around $7 \mathrm{~mm}$. The average deviation between simulations and experiments is less than $0.8{ }^{\circ} \mathrm{C}$. Simulations also show that no-load temperature spans did not change much in regard to the piston stroke.

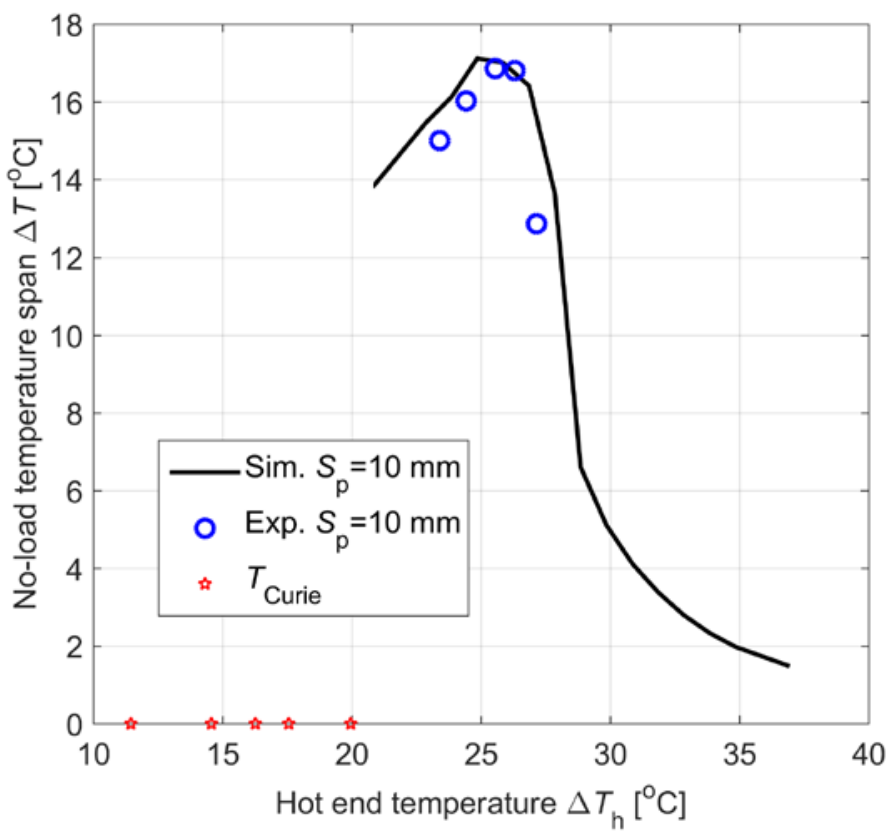

Figure 11. Impact of the hot end temperature on the no-load temperature span of the epoxy bonded AMR.

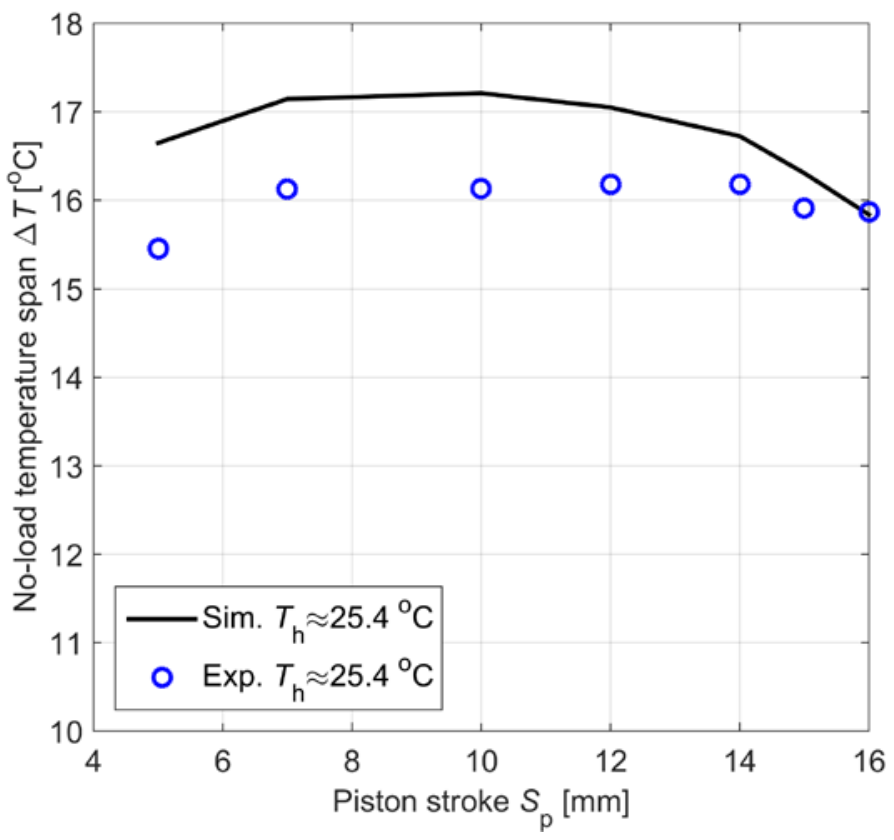

Figure 12. Impact of the piston stroke on the no-load temperature span of the epoxy bonded AMR. 
475

476

Figure 13 presents the results from applying a cooling load when the piston stroke is $10 \mathrm{~mm}$. The hot end temperature in experiments (black dot line) varies slightly for different points and the average value is around $25.4{ }^{\circ} \mathrm{C}$. The regenerator provides $2.8 \mathrm{~W}$ cooling power with $\Delta T=2{ }^{\circ} \mathrm{C}$ and realizes a no-load temperature span of $16{ }^{\circ} \mathrm{C}$. In addition, a batch of simulations is implemented and presented assuming $T_{h}$ ranges from 20.8 to $27.8^{\circ} \mathrm{C}$. Similar to the results in Figure 11, the simulated load curves vary largely even with a small change in $T_{\mathrm{h}}$. In the low $\Delta T$ region with lower $T_{\mathrm{h}}$, higher $\dot{Q}_{\mathrm{c}}$ is obtained and the slope becomes significantly larger. The experimental data fit the curve with $T_{\mathrm{h}}=24.8^{\circ} \mathrm{C}$ better, rather than the one with $T_{\mathrm{h}}=25.4^{\circ} \mathrm{C}$. The reason may lie in the facts that the hot end temperature is fluctuating during each cycle and the real hot end temperature (the reservoir temperature in simulations) is lower than the measured average value.

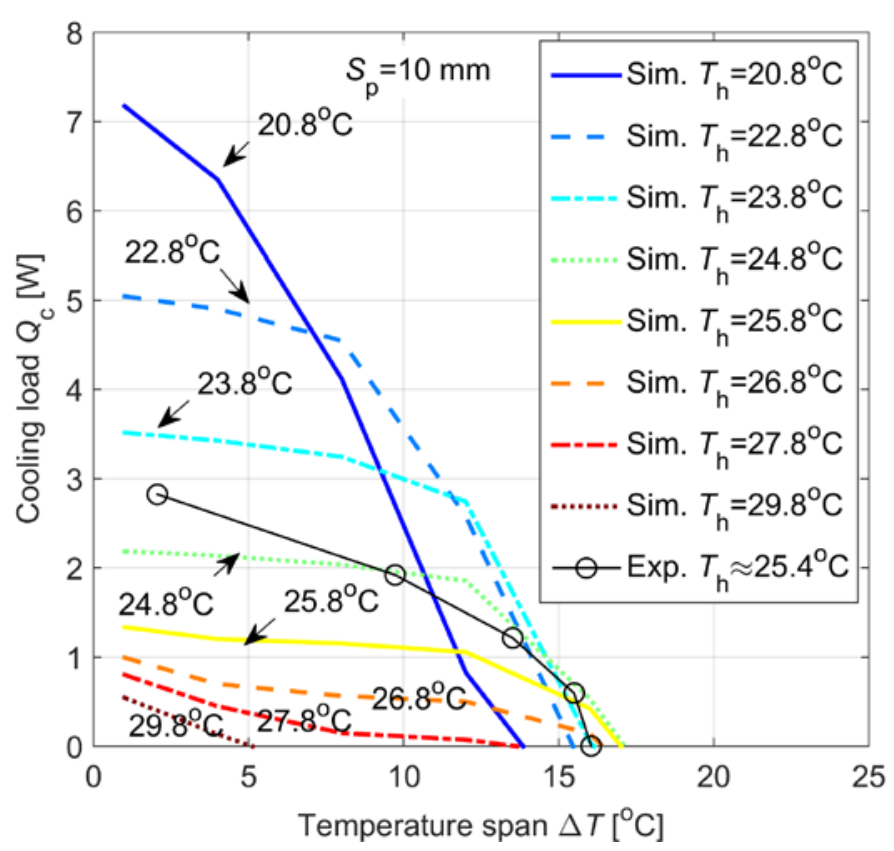

Figure 13. Impact of the working temperature on the cooling load curves of the epoxy bonded AMR.

More cooling load curves are presented in Figure 14 (a) and (b). In Figure 14 (a), the maximum temperature span is about $16{ }^{\circ} \mathrm{C}$ for different piston strokes, and the temperature span decreases when more cooling load is applied. Compared to experimental results, the simulations deviates from the cooling load but still reflect the trends. As discussed previously, the load curve is so sensitive to $T_{\mathrm{h}}$ that any small change in hot end temperature would lead to a considerable change in the device performance, which could be the reason of the deviation. Compared with Figure 14 (a), the experiments in Figure 14 (b) are run with lower $T_{\mathrm{h}}$, realizing higher $\dot{Q}_{\mathrm{c}}$ at the small $\Delta T$ region but smaller no-load temperature span around $13.6^{\circ} \mathrm{C}$. This effect is also reflected in the simulations, reading the curves with $T_{\mathrm{h}}=23.8$ and $25.8^{\circ} \mathrm{C}$ shown in Figure 13. The overall absolute deviations between simulations and experiments in Figure 14 (a) and (b) are about 0.42 and $0.74 \mathrm{~W}$ respectively. The small regenerator achieves a considerable cooling power of $5.7 \mathrm{~W}$ at $\Delta T=9.5^{\circ} \mathrm{C}$ with $S_{\mathrm{p}}=14 \mathrm{~mm}$, as a typical working point. 
500

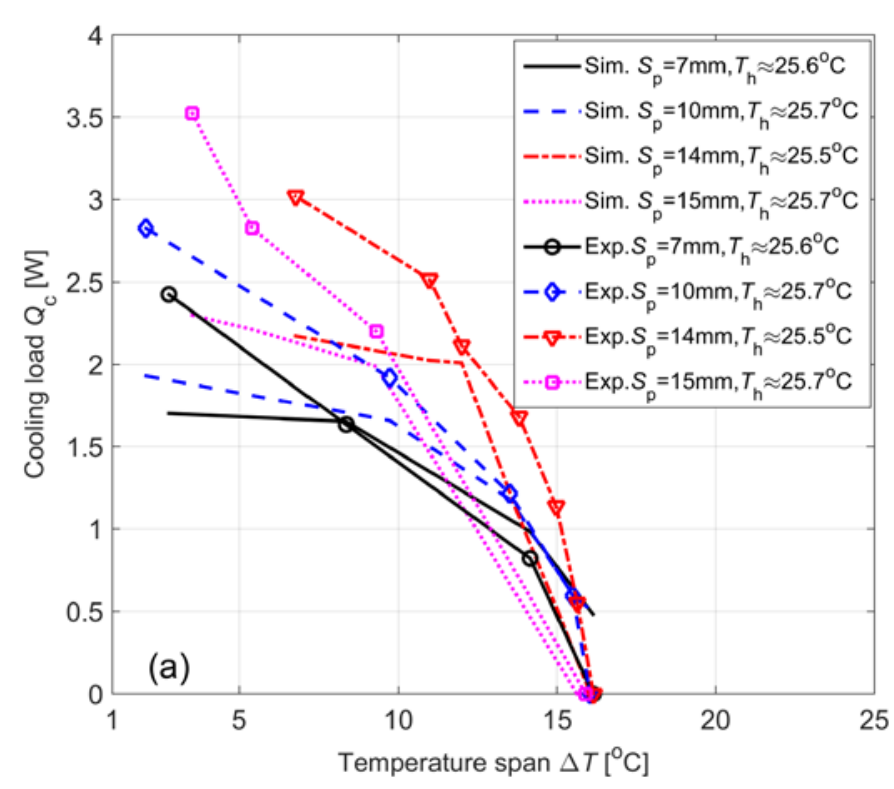

(a) First experiment with higher $T_{\mathrm{h}}$

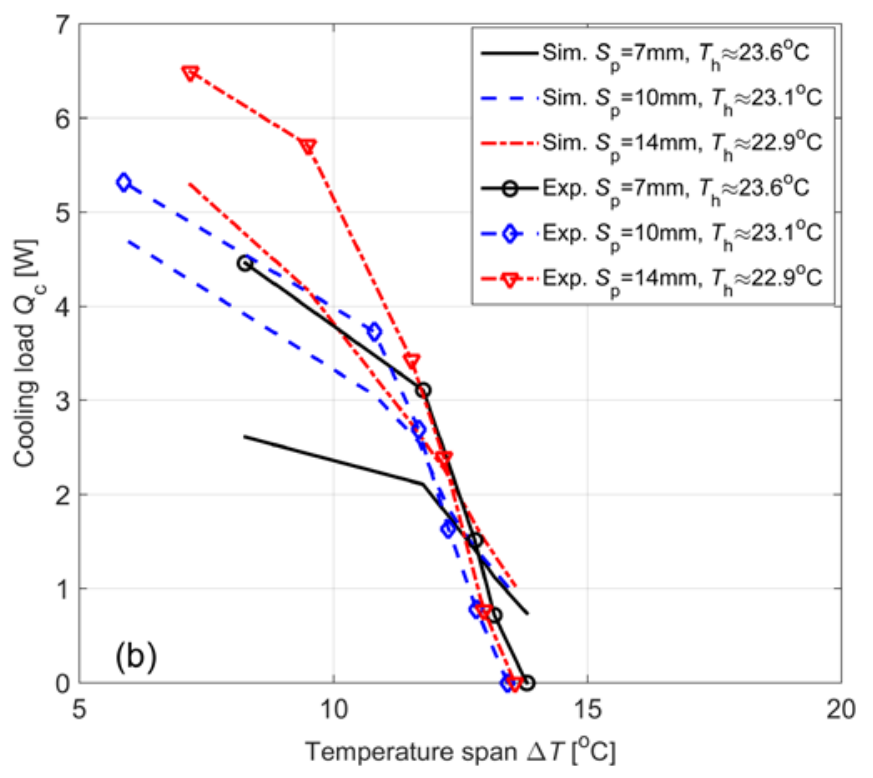

(b) Second experiment with lower $T_{\mathrm{h}}$

Figure 14. Cooling load as a function of the temperature span of the epoxy bonded AMR.

\section{Conclusions}

The passive characterization and active testing of epoxy-bonded regenerators are presented in this study. The epoxy-bonding technique serves to increase the mechanical strength of regenerators using brittle materials and to build monolithic regenerators. The particle size analysis showed that the $\mathrm{La}(\mathrm{Fe}, \mathrm{Mn}, \mathrm{Si})_{13} \mathrm{H}_{\mathrm{y}}$ particles in the first group were quite irregular and had a broader distribution in the particle size compared to the second group of spherical particles. Two epoxy bonded regenerators based on these particles and four reference packed beds loaded with SS particles were tested passively. The friction factors of the SS packed beds fit the classic Ergun equation quite well, while the epoxy bonded regenerator showed a significantly higher $f_{\mathrm{F}}$ than the prediction, especially for the irregular particles. This was due to the high irregularity, the broad distribution in the particle size and the introduction of epoxy. Moreover, the results show that the regenerator loaded with smaller SS particles always yields a higher effectiveness. The epoxy bonded regenerator with the irregular particles exhibited slightly higher effectiveness than that with spherical particles, while the pressure drop over the former was higher. New spherical particles with a smaller diameter of $0.2-0.3 \mathrm{~mm}$ could be interesting for future studies and applications, which has also been investigated theoretically [18]. In addition, the overall Nusselt number of both groups of regenerators fit the trends of Wakao et al.'s and Engelbrecht's correlations and the results in this study fit the latter better. It is noted that the epoxy bonded regenerators show good stability and no failure is observed in a 2-month discontinuous test. Only tiny dusts escape from the regenerator and they are stopped by the screen meshes at each end of the regenerator.

A five-layer epoxy bonded AMR using spherical $\mathrm{La}(\mathrm{Fe}, \mathrm{Mn}, \mathrm{Si})_{13} \mathrm{H}_{\mathrm{y}}$ particles was also tested actively in a small reciprocating magnetic refrigerator. This regenerator realized a maximum no-load temperature span up to $16.8^{\circ} \mathrm{C}$ and provided $5.7 \mathrm{~W}$ of cooling power at a temperature span of $9.5^{\circ} \mathrm{C}$, showing the spherical particles realize a good performance. In addition, the experimental results verify that the AMR using MCMs with a first order phase transition is quite sensitive to the working temperature [25]. To realize the full potential of a layered AMR, all the layers should be activated properly by adjusting the temperature distribution along the regenerator. The 1D numerical model was validated with the experiments, showing the simulations can predict the trends of the AMR performance well. 
532

533

534

535

536

537

538

539

540

541

542

543

544

545

546

547

548

549

550

551

552

553

554

555

556

557

558

559

560

561

562

563

564

565

566

567

568

569

570

571

572

573

574

575

576

577

\section{Acknowledgements}

This work was financed by the ENOVHEAT project which is funded by Innovation Fund Denmark (contract no 12-132673).

\section{References}

1. A. Kitanovski, J. Tušek, U. Tomc, U. Plaznik, M. Ožbolt, and A. Poredoš, Magnetocaloric energy conversion, Springer (2015), doi: 10.1007/978-3-319-08741-2.

2. K. Engelbrecht, D. Eriksen, C. R. H. Bahl, R. Bjørk, J. Geyti, J. A. Lozano, K. K. Nielsen, F. Saxild, A. Smith, and N. Pryds, Experimental results for a novel rotary active magnetic regenerator, Int. J. Refrig. 35 (6) (2012) 1498-1505, doi: 10.1016/j.ijrefrig.2012.05.003.

3. S. Jacobs, J. Auringer, A. Boeder, J. Chell, L. Komorowski, J. Leonard, S. Russek, and C. Zimm, The performance of a large-scale rotary magnetic refrigerator, Int. J. Refrig. 37 (2014) 84-91, doi: 10.1016/j.ijrefrig.2013.09.025.

4. D. Eriksen, K. Engelbrecht, C. R. H. Bahl, R. Bjørk, K. K. Nielsen, A. R. Insinga, and N. Pryds, Design and experimental tests of a rotary active magnetic regenerator prototype, Int. J. Refrig. 58 (2015) 14-21, doi: 10.1016/j.ijrefrig.2015.05.004.

5. J. A. Barclay and S. Sarangi, Selection of regenerator geometry for magnetic refrigerator applications, Technical report, Los Alamos National Laboratory U.S. (1984).

6. A. Rowe, Thermodynamics of active magnetic regenerators: Part I, Cryogenics 52 (2012) 111-118, doi: 10.1016/j.cryogenics. 2011.09.005.

7. A. Fujita, S. Fujieda, Y. Hasegawa, and K. Fukamichi, Itinerant-electron metamagnetic transition and large magnetocaloric effects in $\mathrm{La}\left(\mathrm{Fe}_{\mathrm{x}} \mathrm{Si}_{1-\mathrm{x}}\right)_{13}$ compounds and their hydrides, Phys. Rev. B 67 (2003) 104416, doi: 10.1103/PhysRevB.67.104416.

8. J. Tušek, A. Kitanovski, U. Tomc, and C. Favero, Experimental comparison of multilayered La-FeCo-Si and single-layered Gd active magnetic regenerators for use in a room temperature magnetic refrigerator, Int. J. Refrig. 37 (2014) 117-126, doi: 10.1016/j.ijrefrig.2013.09.003.

9. A. Barcza, M. Katter, V. Zellmann, S. Russek, S. Jacobs, and C. Zimm, Stability and magnetocaloric properties of sintered $\mathrm{La}(\mathrm{Fe}, \mathrm{Mn}, \mathrm{Si}) \mathrm{H}$ alloys, IEEE Trans. Magn. 47 (2011) 3391-3394, doi: 10.1109/TMAG.2011.2147774.

10. V. Basso, M. Küpferling, C. Curcio, C. Bennati, A. Barzca, M. Katter, M. Bratko, E. Lovell, J. Turcaud, and L. F. Cohen, Specific heat and entropy change at the first order phase transition of La(Fe-Mn-Si) $)_{13}-\mathrm{H}$ compounds, J. Appl. Phys. 118 (2015) 053907, doi: 10.1063/1.4928086.

11. T. Lei, K. Engelbrecht, K. K. Nielsen, H. Neves Bez, and C. R. H. Bahl, Study of multi-layer active magnetic regenerators using magnetocaloric materials with a first and second order phase transition, J. Phys. D: Appl. Phys. 49 (2016) 345001, doi:10.1088/0022-3727/49/34/345001.

12. J. Liu, J. D. Moore, K. P. Skokov, M. Krautz, K. Löwe, A. Barcza, M. Katter, and O. Gutfleisch, Exploring $\mathrm{La}(\mathrm{Fe}, \mathrm{Si})_{13}$-based magnetic refrigerants towards application, Scr. Mater. 67 (2012) 584589, doi: 10.1016/j.scriptamat.2012.05.039.

13. S. Fujieda, A. Fujita, K. Fukamichi, Y. Yamazaki, and Y. Iijima, Giant isotropic magnetostriction of itinerant-electron metamagnetic $\mathrm{La}\left(\mathrm{Fe}_{0.88} \mathrm{Si}_{0.12}\right)_{13} \mathrm{H}_{\mathrm{y}}$ compounds, Appl. Phys. Lett. 79 (5) (2001) 653, doi: 10.1063/1.1388157.

14. B. Pulko, J. Tušek, J. D. Moore, B. Weise, and K. Skokov, Epoxy-bonded La-Fe-Co-Si magnetocaloric plates, J. Magn. Magn. Mater. 375 (2015) 65-73, doi: 10.1016/j.jmmm.2014.08.074. 
15. H. Neves Bez, K. Navickaité, T. Lei, K. Engelbrecht, A. Barcza, and C. R. H. Bahl. Epoxy bonded $\mathrm{La}(\mathrm{Fe}, \mathrm{Mn}, \mathrm{Si})_{13} \mathrm{H}_{\mathrm{z}}$ as a multi-layered active magnetic regenerator, Proceedings of the $7^{\text {th }}$ IIF-IIR International Conference on Magnetic Refrigeration at Room Temperature, (2016).

16. M. A. Richard, A. M. Rowe, and R. Chahine, Magnetic refrigeration: single and multimaterial active magnetic regenerator experiments, J. Appl. Phys. 95 (4) (2004) 2146-2150, doi: 10.1063/1.1643200.

17. M. Krautz, A. Funk, K. P. Skokov, T. Gottschall, and J. Eckert, A new type of $\mathrm{La}(\mathrm{Fe}, \mathrm{Si})_{13}$-based magnetocaloric composite with amorphous metallic matrix, Scr. Mater. 95 (2015) 50-53, doi: 10.1016/j.scriptamat.2014.10.002.

18. T. Lei, K. Engelbrecht, K. K. Nielsen, and C. T. Veje, Study of geometries of active magnetic regenerators for room temperature magnetocaloric refrigeration, Appl. Therm. Eng. 111 (2017) 1232-1243, doi: 10.1016/j.applthermaleng.2015.11.113.

19. T. E. W. Schumann, Heat transfer: A liquid flowing through a porous prism. J. Franklin Institute, 208 (3) (1929) 405-416, doi: 10.1016/S0016-0032(29)91186-8.

20. S. Schopfer, Experimental and numerical determination of thermohydraulic properties of regenerators subjected to oscillating flow, Ph.D. thesis, University of Victoria (2011).

21. P. Trevizoli, Y. Liu, A. Tura, A. Rowe, and J. Barbosa, Experimental assessment of the thermalhydraulic performance of packed-sphere oscillating-flow regenerators using water, Exp. Therm. Fluid Sci. 57 (2014) 324-334, doi: 10.1016/j.expthermflusci.2014.06.001.

22. K. Engelbrecht, A numerical model of an active magnetic regenerator refrigerator with experimental validation, Ph.D. thesis, University of Wisconsin-Madison (2008).

23. M. Frischmann, K. Engelbrecht, G. Nellis, and S. Klein. Heat transfer coefficient in a packed sphere regenerator for use in active magnetic regenerative refrigeration, Proceedings of the 2008 International Refrigeration and Air Conditioning Conference (2008).

24. B. S. Baclic and G. D. Dragutinovic, Operation of counterflow regenerators, WIT Press (1998).

25. T. Lei, K. K. Nielsen, K. Engelbrecht, C. R. H. Bahl, H. Neves Bez, and C. T. Veje, Sensitivity study of multi-layer active magnetic regenerators using first order magnetocaloric material $\mathrm{La}(\mathrm{Fe}, \mathrm{Mn}, \mathrm{Si})_{13} \mathrm{H}_{\mathrm{y}}$, J. Appl. Phys. 118 (2015) 014903, doi: 10.1063/1.4923356.

26. C. Shin, Tortuosity correction of Kozeny's hydraulic diameter of a porous medium. Physics of Fluids 29 (2017) 023104, doi: 10.1063/1.4976550.

27. S. Ergun and A. A. Orning, Fluid flow through randomly packed columns and fluidized beds, Ind. Eng. Chem. 41 (6) (1949) 1179-1184, doi: 10.1021/ie50474a011.

28. S. Ergun, Fluid flow through packed columns, Chemical Engineering Progress 48 (2) (1952) 89-94.

29. EES, Engineering equation solver, Technical report, F-Chart Software LLC. (2016).

30. N. Wakao, S. Kaguei, and T. Funazkri, Effect of fluid dispersion coefficients on particle to fluid heat transfer coefficients in packed beds: correlation of Nusselt numbers, Chem. Eng. Sci. 34 (3) (1979) 325-336, doi: 10.1016/0009-2509(79)85064-2.

31. K. Engelbrecht, C. R. H. Bahl, and K. K. Nielsen. Experimental results for a magnetic refrigerator using three different types of magnetocaloric material regenerators, Int. J. Refrig. 34 (4) (2011) 1132-1140, doi: 10.1016/j.ijrefrig.2010.11.014.

32. R. I. Joseph, Ballistic demagnetizing factor in uniformly magnetized cylinders, J. Appl. Phys. 37 (1966) 4639, doi: 10.1063/1.1708110.

33. D. Velazquez, M. Castro, and E. Palacios, Practical properties of LaFeCoSi materials to be used in magnetic cooling regenerators, Proceedings of $6^{\text {th }}$ IIF-IIR International Conference on Magnetic Refrigeration at Room Temperature (2014). 